\title{
Analysis of Java Island's ozone layer and ultra violet index variability based on satellite data
}

\author{
Ninong Komala ${ }^{1, *}$ \\ ${ }^{1}$ Center for Atmospheric Science and Technology of LAPAN, Jalan Dr. Djundjunan 133 Bandung, 40173, Indonesia
}

\begin{abstract}
The ozone layer has a very important role in our atmosphere because it can protect every living on the surface of the earth against harmful Ultra Violet-B radiation. This study aims to discuss and analyze the linkages of ozone layer and Ultra Violet index (UVI) in Java Island and using of FFT to find the period that dominates the ozone layer and UVI variation. The results obtained are characteristic of ozone layer and UVI as well as linkage of UVI to ozone layer in Java Island. Using data of the Ozone Monitoring Instrument (OMI) sensor on AURA satellites from 2005-2016 has been obtained monthly, seasonal and annual characteristics for ozone and UVI and the period dominating the variation of the ozone layer and UVI. The ozone layer varied between $238 \mathrm{DU}$ to $277 \mathrm{DU}$, the annual variation pattern peaked in October and the minimum in January. The UVI varies between 7.8 and 13.6. The annual variation of UVI peaked in October and the minimum in June. Linear regression of the UVI with ozone in December, January and February (DJF) showed a negative correlation coefficient of 0.77 which means there is a strong correlation between decreasing of ozone concentration with increasing of UVI. Variability of Java Island's ozone layer is dominated by six month, 12-months and 28-months cycles. While UVI most dominated by the cycle of 6 months and 12 months.
\end{abstract}

\section{Introduction}

Life system on earth can be protected from Ultra Violet radiation due to the absorption of UV radiation by ozone, especially ozone in the stratosphere layer. Most of the ozone in the atmosphere is in the stratospheric layer $(90$ $\%)$ therefore called the ozone layer. The remainder (10 $\%)$ is in the troposphere layer and other layers. The ozone layer is the concentrated ozone in the stratosphere layer at $10-50 \mathrm{~km}$ above the earth's surface. The thickness of this layer illustrates the amount of ozone concentration in the coating. Total ozone is a vertical density (number of ozone molecules of broad unity) at 0 ${ }^{\circ} \mathrm{C}$ and 1 atmospheric pressure. The unit used is DU (Dobson Unit). $1 \mathrm{DU}=2.69 \times 10^{16}$ molecules $/ \mathrm{cm}^{2}$. Total ozone is used to represent the ozone layer condition. In this paper the ozone layer data also uses the Dobson Unit (DU) unit. The solar radiation that reaches the Earth's surface is significantly affected by ozone changes, high UV radiation can affect human health [1]. Therefore, studies of temporal variability of the ozone layer and UV radiation become a priority for scientific research [17]. The UV index (UVI) is designed to represent UV weighted erythema radiation in a simple form. So, we can get an overview of the UVI [2]. Long-term observation and monitoring results show that ultraviolet radiation reaching the Earth's surface is increasing in response to the depletion of the ozone layer. The results show that: the amount of UV-B radiation that reaches the surface of the earth at a particular location is highly dependent on the amount/condition of the ozone layer in the area. When this ozone-depleting condition occurs in the stratosphere or in the troposphere, the total amount of ozone is reduced and the amount of ultra violet radiation reaching the earth's surface will increase proportionally. The relationship between total ozone and UV-B radiation has been demonstrated in many locations by taking direct measurements of ozone and UV-B radiation. Another thing that causes UV-B radiation changes to the surface of the earth depends also on several factors such as sun position that changes daily and seasonally cycles, local cloud conditions, altitude location, the amount of ice or snow cover and the amount of atmospheric particles (aerosols) in the atmosphere above that location. Changes in cloud and aerosol conditions are also related to the condition of air pollution and GHG emissions from human activities [3, 4]. The global distribution of UV radiation and its seasonal change compared to long-term changes in atmospheric composition obtained significant correlation results between time series of ozone and UV indices i.e. decreasing ozone resulting in an increase in UVI in New Zealand. The UVI is defined as a unit with no linearly related unit to erythema dose rate, i.e. the size of human skin relevant to the intensity of UV radiation on the Earth's surface. 1 UVI is equal to $25 \mathrm{~mW} / \mathrm{m}^{2}$ [5]. Longterm observations and monitoring indicate that ultraviolet radiation reaching the Earth's surface will increase in response to the depletion of the ozone layer. UV radiation is also stronger in summer and weak in winter. Clouds, particulates, aerosols and contaminants can absorb and disperse some UV radiation, thereby reducing the amount of UV radiation reaching the Earth's surface [4]. Specific studies show that clouds, ozone and

\footnotetext{
* Corresponding author: ninongk@yahoo.com; ninong.komala@lapan.go.id
} 
atmospheric aerosols are atmospheric compounds that mainly attenuate the UV that reaches the surface of the earth [6]. The study of ozone and UV indices in Java aims to investigate and analyze changes in the UVI due to variations in the ozone layer. This research is part of a series of researches that support and realize the development of atmospheric compositions using satellite data [7] which is very useful for databases and to support the study of atmospheric characteristics in several regions of Indonesia.

\section{Research methods}

The data used in this study is the ozone layer data (DU) and UVI in Java Island area $\left(5.5^{\circ} \mathrm{S}-8.75^{\circ} \mathrm{S}\right.$ and $105^{\circ} \mathrm{E}-$ $\left.115^{\circ} \mathrm{E}\right)$ as an observation result of Ozone Monitoring Instrument (OMI) from the AURA satellite obtained from NASA's data provider website. The data obtained is a monthly global average data with $1^{\circ}$ latitude $\times 1^{\circ}$ longitude grid. The data period used in this study is from 2005 to $2016[1,8]$. The research methodology is to extract ozone data and UVI for Java Island region from global OMI-AURA data in Net CDF format for period of 2005 to 2016. Convert data from Net CDF format for ozone data and UVI using HDF view and EXCEL. Then the data is processed with time series analysis to obtain seasonal and annual variations. Statistical analysis is also performed to obtain UVI and ozone correlation that will explain the effect of UVI on ozone variation. Fast Fourier Transform (FFT) analysis is also used to find the dominant period affecting the ozone layer and UVI variation in Java Island [9].

\section{Results and discussions}

Result of the ozone layer and UVI temporal variation from 2005-2016 in Java Island is presented in Figure 1.

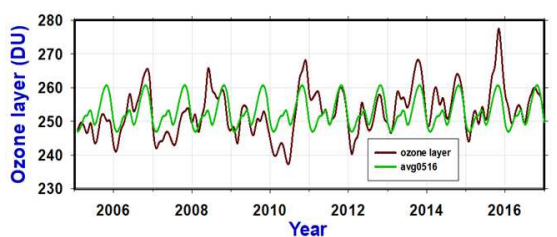

(a)

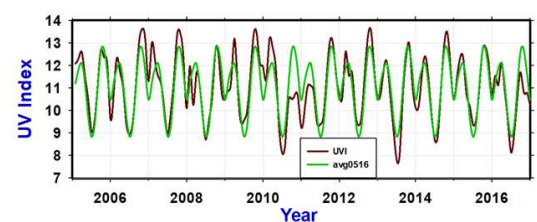

(b)

Fig. 1. Temporal variation of ozone layer (a) and UVI (b) in Java Island in 2005-2016.

Figure 1 (a) show that in the period 2005 to 2016, the ozone layer in Java varied between 238 DU-277 DU. In general, peak of the ozone layer in 2005, 2007 and early 2010 was lower than the annual pattern in other years, while the annual pattern in 2015 was highest. The lowest ozone layer in Java was detected in May of 2010 (238.3
DU) and the highest ozone layer occurred in October of 2015 (277.5 DU). The temporal variation of the Java Island UVI in 2005 to 2016 in Figure 1 (b) illustrates the variation between 7.84-13.62. The lowest UVI occurred in June 2013 (7.84) and the highest UVI occurred in October 2006 (13.62). The peak of the UVI in 2006 and 2012 is higher than in other years while the UVI 2010 and 2013 annual pattern is lower than UVI average annual pattern of 2005-2016.

To illustrate the differences in the characteristics of ozone and the UVI on the island of Java are made in Figure 2 which shows the deviation of temporal variation to the mean value of 2005-2016.

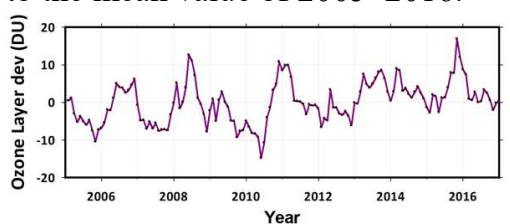

(a)

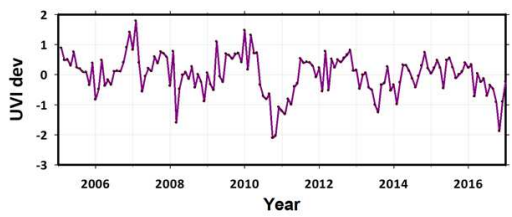

(b)

Fig. 2. Deviation of temporal variation of the ozone layer (a) and UVI (b) against the average value of 2005-2016.

In Figure 2 (a) the deviation of Java total ozone is presented in the time series from January 2005 to December 2016 which also shows an annual pattern. Ozone layer deviation in Java varies between -15 DU and 17 DU. The negative deviation of ozone in Java occurred in 2005 and 2010, while high positive deviations occurred in 2006, 2008 and 2015. In Figure 2 (b), the Java Island UVI deviation also shows an annual pattern. The deviation of the UVI varied between -2 and 2. The highest negative deviation for UVI in Java occurred in 2008, 2010 and 2016, whereas the highest positive deviation occurred in 2006 and 2009. Negative ozone deviations and UVI indicate that in those years they were lower than the average value of 2005-2016. While the positive deviation shows that in those years they were higher than the average value of 2005-2016.

Figure 3 shows the average annual pattern of the ozone layer and UVI in Java Island obtained by making average of its annual pattern from 2005-2016.

In Figure 3 (a) there is a pattern of annual variations in the ozone layer in Java with ozone values between 240 DU-270 DU. Ozone peaked in October (260 DU with 7.56 DU standard deviation) and minimum occurred in January (246 DU with 5.52 DU standard deviation).

Figure 3 (b) shows the annual variation pattern of the UV index that peaked in October (12.71 with a standard deviation of 1.0) and the minimum occurred in June (8.85 with a standard deviation of 0.56 ). 


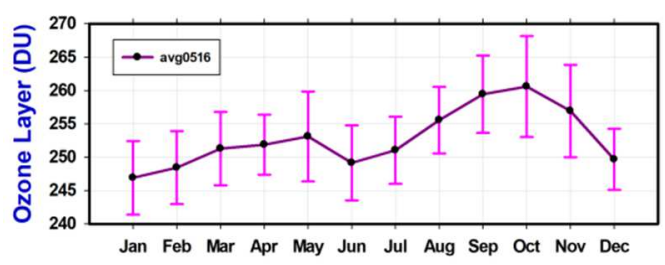

(a)

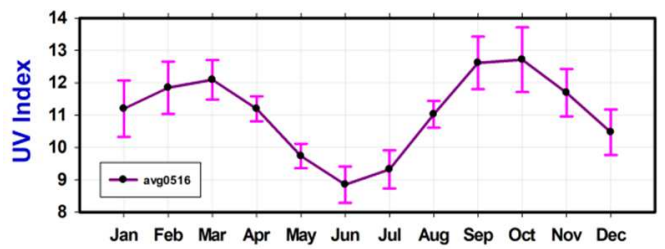

(b)

Fig. 3. Pattern of annual variation of ozone layer (a) and UVI (b) in Java Island in 2005-2016 along with its standard deviation.

To obtain the seasonal characteristics of ozone and UVI then the time series of seasonal variations were made for the months December, January, February (DJF), March, April, May (MAM), June, July, August (JJA) and September, October, November (SON) from 2005-2016 as shown in Figure 4.

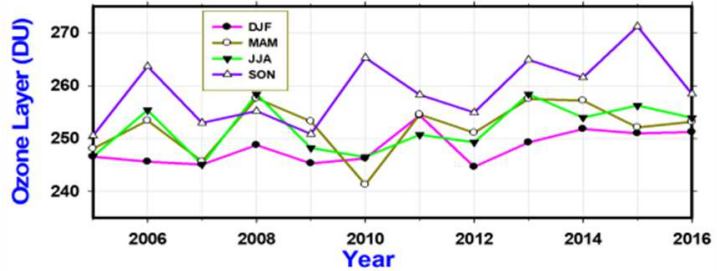

(a)

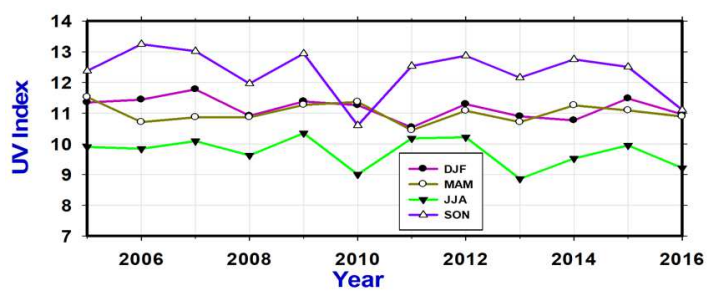

(b)

Fig. 4. Seasonal variation of ozone layer (a) and UVI (b) in Java Island in 2005-2016.

Analysis of ozone seasonal variation in Java Island is shown in Figure 4 (a), the seasonal variation pattern of the ozone layer varies between 241.31 DU-271.22 DU. The ozone variation in SON indicated a higher value during 2005-2016 and the lower at DJF. The seasonal variation of the ozone layer of Java Island for the DJF is between 244.68 DU-254.39 DU, with the lowest ozone layer occurring at the DJF of 2012 (244.68 DU) and the highest in 2011 (254.39 DU). In MAM range of ozone layer between 241.31 DU-257.62 DU, lowest ozone layer happened at MAM year of 2010 (241.31 DU) and highest in 2008 (257.62 DU). For the JJA the ozone layer range is between 245.12 DU-258.40 DU. The ozone layer in the SON has a range of 250.57 DU-
271.22 DU, with the lowest ozone layer occurring in 2005 (250.57 DU) and the highest occurring in the SON of 2015 (271.22 DU). Overall, it is shows that the highest seasonal variation of ozone layer occurs in the SON and the lowest is in the DJF.

Seasonal variation patterns of Java Island's UVI for DJF, MAM, JJA and SON 2005 through December 2016 is shown in Figure 4 (b). Seasonal variation of UVI ranged in between 8.86-13.25. The average of UVI seasonal variation from 2005-2016 showed that UVI reaching maximum in SON and minimum in JJA. Seasonal variation of UVI for DJF was between 10.5411.78 , with the lowest UVI occurring at DJF in 2011 (10.54) and the highest in 2007 (11.78). MAM of UVI ranged in between 10.44-11.5 with the lowest UVI occurs in MAM 2011 (10.44) and the highest in 2015 (11.53). For JJA the UVI varies from 8.86 to 10.35 . The lowest UVI occurred at JJA in 2013 (8.86) and the highest in 2009 (10.35). The UVI in SON has a range of 10.60-13.25, with the lowest UVI occurred in 2010 (10.60) and highest at SON 2006 (13.25).

The deviation of ozone seasonal variation and UVI is presented in Figure 5. The deviation value of seasonal variation gives information on ozone seasonal variation and UVI which is higher or lower than the 2005-2016 seasonal average.

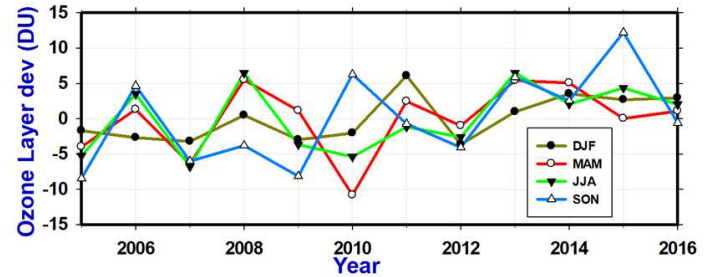

(a)

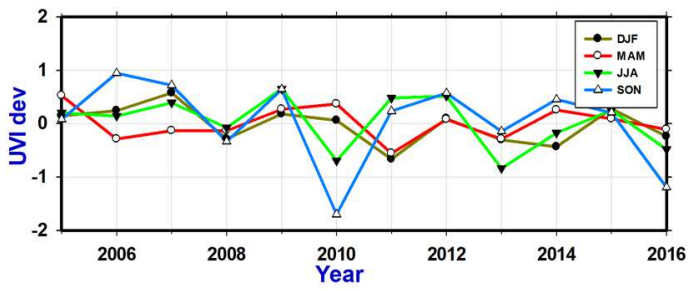

(b)

Fig. 5. Deviation of seasonal variations of the ozone layer (a) and UVI (b) against the 2005-2016 average.

In Figure 5 (a), the deviation of seasonal variations in the ozone layer varies between -10.79 DU to $12.22 \mathrm{DU}$. The deviation for the DJF between -3.62 DU to 6.09 DU, with the minimum deviation occurring in the DJF of 2012 ( -3.62 DU) and the highest positive deviation in 2011 (6.09 DU). Seasonal deviation of ozone layer at MAM between -10.79 DU to 5.52 DU. The minimum deviation occurred at MAM in 2010 (-10.79 DU) and the highest positive deviation in 2008 (5.52 DU). For the JJA the deviation range is $-6.78 \mathrm{DU}$ to $6.50 \mathrm{DU}$. The minimum ozone layer deviation occurred at JJA in 2007 ( -6.78 DU) and the highest positive deviation in 2013 (6.50 DU). The deviation of the ozone layer in the SON has a range of $-8.43 \mathrm{DU}$ to $12.22 \mathrm{DU}$, with the minimum 
deviation in 2005 (-8.43 DU) and the highest positive deviation occurs in 2015 (12.22 DU).

In Figure 5 (b), deviation of seasonal variations of the UVI is varying between -0.84 to 0.95 . The seasonal variation deviation of the UVI for the DJF is between 0.66 to 0.58 . The minimum deviation of the UVI occurs in the $2011(-0.66)$ and the highest positive deviation in 2007 (0.53). Deviation of UVI on MAM is between 0.56 to 0.53 . Minimum deviation occurred in the MAM $2011(-0.56)$ and the highest positive deviation in 2005 (0.53). For JJA the deviation is between -0.84 to 0.65 . The minimum deviation occurred at JJA of $2013(-0.56)$ and the highest positive deviation in 2009 (0.65). The deviation in the SON varies between -1.70 to 0.95 , with the minimum deviation in $2010(-1.70)$ and the highest positive deviation occurring in the SON of $2006(0.95)$.

Relationship between the seasonal variations of ozone layer with UVI in Java Island based on the scatter plot is presented in Figure 6.
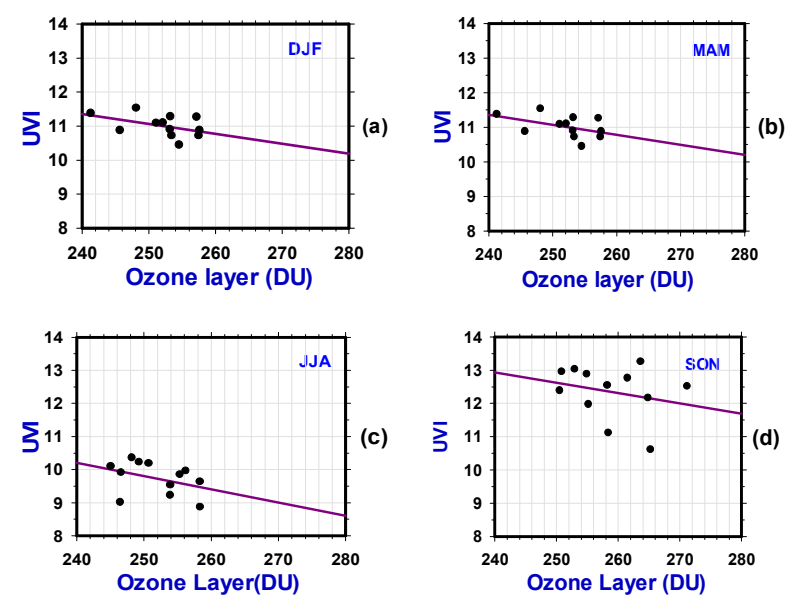

Fig. 6. Graphic of the correlation of ozone layer with UVI in Java Island in DJF (a), MAM (b), JJA (c), and SON (d).

Scatter plots between UVI and the ozone layer result linear regression equations. The equations resulting from the plot of the ozone layer concentration and the UV indices can be seen in Table 1 .

Table 1. Equation between UVI and ozone layer in Java Island.

\begin{tabular}{|c|c|c|c|}
\hline Season & Regression equation & $\boldsymbol{R}^{2}$ & $\boldsymbol{r}$ \\
\hline DJF & $y=-0.086 x+32.478$ & 0.601 & 0.775 \\
\hline MAM & $y=-0.029 x+18.340$ & 0.210 & 0.459 \\
\hline JJA & $y=-0.039 x+19.790$ & 0.150 & 0.387 \\
\hline SON & $y=-0.031 x+20.394$ & 0.064 & 0.253 \\
\hline
\end{tabular}

The equation obtained for the DJF season is:

$$
y=-0.086 x+32.478
$$

where $y$ is the UVI and $x$ is the ozone layer.
The coefficient of determination obtained is 0.601 and the correlation coefficient between the UVI and the ozone layer is 0.775 . From the obtained equation, it means that $60.10 \%$ of UVI variable can be explained by ozone layer variable at the equation, while the rest cannot be explained by ozone layer variable because it depends on other variable. For other seasons of MAM, JJA and SON correlation coefficient are $0.77,0.45,0.38$ and 0.25 . Statistical analysis of the correlation between seasonal variation of UVI and ozone layer in Java give the result of negative correlation. It is mean that the increase of UVI is due to the decreasing (depletion) of ozone layer or, in other word, the thicker the ozone layer the lower the UVI. The highest correlation occurred in the DJF season with a correlation coefficient of 0.77 .

Result of the Fast Fourier Transform (FFT) analysis to find the dominant period affecting the ozone layer and UVI variation in Java Island is shown in Figure 7.

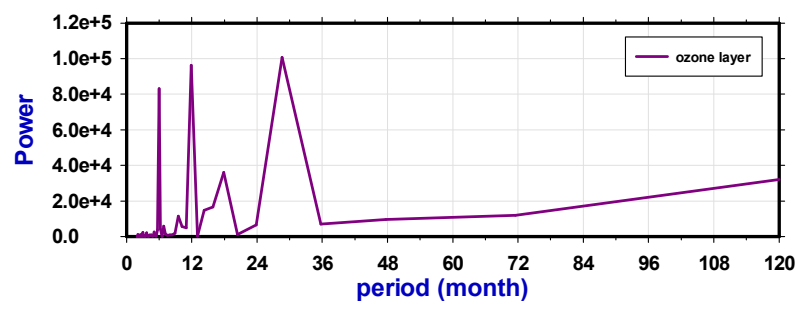

(a)

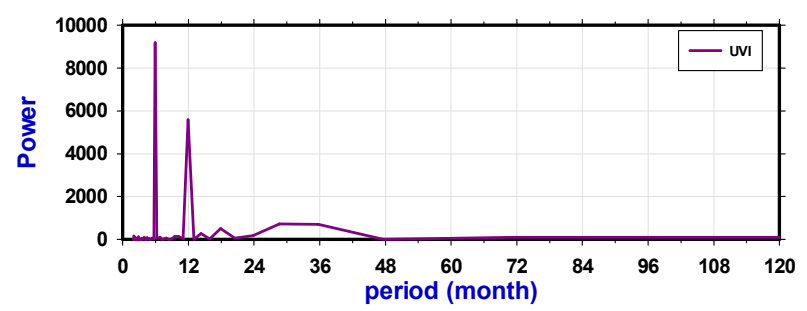

(b)

Fig. 7. Graph of the FFT results for ozone layer (a) and for UVI (b) in Java Island.

Figure 7 (a) show the FFT result of the 12 years monthly data of ozone layer (2005-2016). It was found that ozone layer data are sensitive to the 6 months, 12 months and 28 months variability. In Figure 7 (b), the FFT result of UVI data are sensitive to the 6 month, 12 months and the 28 months variability show lower. Comparison of the FFT results for ozone and UVI shows there is a similarity in the dominant period of 12 months. These two variables also have a 6-month period of dominance. If only the ozone variable to be considered, the period of 28 months (or almost 2.5 years) also shows that there is a dominant occurrence with this period. However, this is not indicated in the UVI variable.

Analysis of the ozone layer in Java Island in 2005 to 2016 obtained the variation from 238 DU to 277 DU. These values correspond to the ozone layer in the equator region that is varying from $240 \mathrm{DU}$ to $270 \mathrm{DU}$. The ozone at the equator is lower than in the mid and high latitudes. The correlation value between ozone layer and Java Island UV index in each season has different value. According to $[4,10]$, it is indicated that the sun's position and season factor over an area affects the value 
of the ozone layer and the UV index. Aerosol and air pollutant factors can also absorb and disperse some UV radiation and thus reduce the amount of UV radiation that can reach the surface of the earth. This is influenced also by the local and season factors. Since the level of UV radiation that reaches us each day is impacted by a number of factors, this can be the reason why the UV level fluctuates from day to day, or why you get sunburnt when you think that you are safe. The total annual variation pattern of ozone and the UVI in Java Island obtained has a different pattern than that obtained in $[7,5,10]$.

The UVI in Java Island is between 8 to 13.6. This value is already classified as very high to extreme [14] (Figure 4). Based on the observation results it can be informed that the long-term conditions of ozone and UVI in Java, the importance of accurate data on solar UV radiation is required for UV trends study. This data is also required for photochemical studies of atmospheric and human health protection against UV effects. To obtain UV data in various areas, UV monitoring networks need to be established in many countries [11].

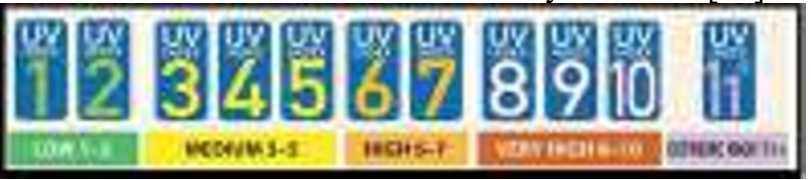

Fig. 8. The UVI scale; values of the index range from zero upward. The higher the UVI, the greater the potential for making damage to the living condition, i.e. skin, eye and plantation, and the less time it takes for harm to occur $[12,13]$.

\section{Conclusion}

Results of the ozone layer and UVI analysis in Java Island based on OMI-AURA data from 2005-2016 gave the variation of ozone layer between 238 DU to 277 DU. The values obtained correspond to the ozone layer values in the equator region which is varying from $240 \mathrm{DU}$ to 270 DU. The UVI in Java Island is between 8 to 13.6, which is categorized as a very high to extreme UV index. It will be very risky for us when doing activities outside without using sun protection, since the higher the UVI the greater the rate of skin dosage and the eyes are damaged by UV irradiation.

The correlation results indicate that there is a strong correlation between the UVI and the ozone layer. The relationship between the UVI and the ozone layer shows a negative relationship. If the ozone layer decreases, the UV index will increase and vice versa. FFT result of the ozone and UVI shows that the 6 months, 12 months and 28-month period affecting both ozone and UVI variation even the power spectrum is different.

The author would like to thank the atmospheric composition data providers of the AURA satellite in particular the NASA MIRADOR website also to the Center for Atmospheric Science and Technology of LAPAN that has supported this research.

\section{References}

1. MIRADOR at (http://mirador.gsfc.nasa.gov/).

2. V. Fioletov, James B. Kerr, Angus Fergusson, "The UV Index: Definition, distribution and factors affecting it." Can J Public Health, 101 (4): I5-I9 (2010)

3. R.L. McKenzie, P.V. Johnston, D. Smale, B.A. Barry, and S. Madronich. "Altitude effects on UVspectral irradianc deduced from measurements at Lauder, ew Zealand, and at Mauna Loa Observatory, Hawaii." J. Geophys. Res. 106, 22845-22860 (2001)

4. UNEP, Annual Report (2010)

5. R.L. McKenzie, "UV radiation climatology and trends", National Institute of Water \& Atmospheric Research (NIWA), Lauder, Central Otago, New Zealand, Presented at PMOD/WRC Meeting, Davos, 18-20 September 2007 (2007)

6. WMO, Sci. Assess. of Ozone Depletion: 2010, Global Ozone Research and Monitoring ProjectReport No. 52, 516 pp., Geneva, Switzerland (2011)

7. N. Komala, A. Budiyono, N. Ambarsari, Thohirin, H. Suherman dan E. Adetya. "Karakteristik ozon total dan parameter atmosfer Indonesia dari satelit AURA." Program Penelitian Pusfatsatklim, (2009)

8. J.G. Ackerand, S.G. Leptoukh, "Online analysis enhances use of NASA Earth Science Data"; Eos. Trans. AGU.Vol. 88, No.2, pages 14 and 17 (2007)

9. M.L. Akinyemi, Australian Journal of Basic and Applied Sciences, 2(4): 1129-1136 (2008)

10. C.S. Zerefos, "Long-term ozone and UV variations at Thessaloniki, Greece", Physics and Chemistry of the Earth, 27, 455-460 (2002)

11. S. Janjai, S. Buntung, R. Wattan and I. Masiri. "Mapping solar ultraviolet radiation from satellite data in a tropical environment", Remote Sensing of Environment, 114, 682-691 (2010)

12. US EPA (Environmental Protection Agency), at http://http.epa.gov/sunwise/

13. WHO, Global Solar UV Index, A Practical Guide (2002) 